\title{
Nível de satisfação como diferencial: um estudo de caso em cooperativa de crédito no Mato Grosso do Sul
}

\author{
Satisfaction level as a differential: a case study in a credit union in Mato Grosso do Sul
}

\begin{abstract}
Resumo
Este artigo visa identificar e analisar o nível de satisfação dos associados de uma cooperativa de crédito, em relação ao atendimento, produtos e serviços prestados por esta unidade. A satisfação dos associados é uma das principais formas das cooperativas de crédito conquistarem mercado, ocorrendo a partir da captação e relacionamento. Cooperados exigentes movem as cooperativas a buscar aprimorar seu conhecimento e qualidade, tendo como principal objetivo a satisfação. Para tanto se realizou um estudo de caso na cooperativa, identificando através de entrevistas com os associados seu nível de satisfação. Na realização do estudo utilizaram-se os métodos exploratório e descritivo, os dados foram analisados de forma qualitativa e quantitativa. Os resultados demonstram um bom índice de satisfação dos associados, o atendimento é considerado como um diferencial apresentando cerca de $90 \%$ de avaliação positiva. Em relação aos produtos e serviços comprovou-se ser adequada a demanda, já que 9o\% dos associados avaliam serem ótimos e excelentes, de modo geral os associados estão satisfeitos com a cooperativa, porém existem pontos que devem ser melhorados.
\end{abstract}

Palavras-chave: satisfação. relacionamento. atendimento. qualidade.

\begin{abstract}
This article aims to identify and analyze the level of satisfaction of members of a credit union, in relation to the attendance, products and services provided by this unit. The satisfaction of members is one of the main ways for credit unions to conquer the market, occurring from fundraising and relationships. Demanding members move the cooperatives to seek to improve their knowledge and quality, with satisfaction as the main objective. To this end, a case study was carried out at the cooperative, identifying its level of satisfaction through interviews with members. In carrying out the study, exploratory and descriptive methods were used, the data were analyzed in a qualitative and quantitative way. The results show a good level of satisfaction of the associates, the service is considered as a differential with about $90 \%$ of positive evaluation. In relation to products and services, demand has proven to be adequate, since $90 \%$ of the associates consider themselves to be great and excellent, in general the associates are satisfied with the cooperative, but there are points that must be improved.
\end{abstract}

Keywords: satisfaction. relationship. attendance. quality.

Marlene Forest ${ }^{\mathrm{I}}$, Obedias Miranda Belarmino II.

${ }^{\text {I } U n i v e r s i d a d e ~ E s t a d u a l ~ d e ~ M a t o ~ G r o s s o ~ d o ~ s u l ~-~ U E M S . ~ p r o f m a r l e n e f o r e s t @ g m a i l . c o m ~}$

${ }^{\text {II }}$ Universidade Estadual de Mato Grosso do sul - UEMS. obedias.miranda.22@hotmail.com 


\section{Introdução}

Nos últimos anos, a sociedade vem passando por diversas mudanças na área econômica fator este que resultou em grandes mudanças no planejamento das empresas em especial nas cooperativas de crédito, onde buscar a satisfação dos associados se tornou de extrema importância para sobrevivência do negócio. De acordo com Kotler (2005, p. 42) a "Satisfação consiste na sensação de prazer ou desapontamento de uma pessoa resultante da comparação entre o desempenho ou resultado percebido de um produto e suas expectativas".

Os clientes são a principal razão de existência de qualquer empresa e satisfazê-los deve ser o principal foco das organizações. Afinal, são eles que possibilitam o desenvolvimento da empresa em um mercado cada vez mais competitivo. Por isso, estar atendo às necessidades dos clientes é imprescindível. Nesse cenário as organizações necessitam antecipar-se às mudanças para obterem vantagens competitivas. A satisfação possibilita a fidelização dos clientes e a conquista de novos. Muitos fatores influenciam na satisfação tais como: qualidade dos produtos e serviços, prazos adequados na entrega, preços, atendimento entre outros. Cada vez mais as empresas estão atentas a satisfazer as necessidades e desejos de seus clientes, uma vez atendidas essas necessidades a tendência de que o cliente volte a consumir os produtos e serviços da empresa é maior comparado com a não satisfação dos mesmos.

Os clientes estão cada vez mais exigentes, tornando-se mais insatisfeitos com falhas no atendimento recebido. O número de reclamações nos departamentos de atendimento vem crescendo consideravelmente. Apesar de que menos de $5 \%$ dos clientes insatisfeitos reclamam. Os demais preferem transmitir sua insatisfação para outras pessoas. Pesquisas apontam que $90 \%$ dos clientes insatisfeitos nunca mais voltarão. (SEBRAE, 2017). Além disso, o custo para se conseguir um novo cliente é cinco vezes maior do que para manter um cliente atual (SHIOZAWA, 1993).

Desta forma, observa se que a confiança mútua e a satisfação são consideradas fatores relevantes na constituição de cooperativas de crédito, por se tratar de uma sociedade de pessoas que buscam os mesmos ideais, econômicos, sociais e culturais. Também é a confiança um dos elementos que permite que as cooperativas consigam captar a poupança e os fundos de reserva da população e é a satisfação com o serviço prestado que garante a permanência desses valores investidos junto à cooperativa. (BURIGO, 2010, p. 426). Frente a isso, torna-se necessário que as cooperativas de credito estejam atentas ao fator de satisfação dos cooperados, uma vez que, um dos grandes diferenciais das cooperativas é o atendimento prestado de forma mais simples e próxima onde o associado também são donos do negócio podendo votar e ser votado cooperando assim no crescimento e desenvolvimento da cooperativa, por ser dono do negócio a questão satisfação torna-se um ponto crucial para o sucesso dessas instituições uma vez que a satisfação é o que garante a permanência do cooperado.

De acordo com o exposto, o presente artigo tem como objetivo identificar e analisar o nível de satisfação dos associados de uma cooperativa de crédito no Mato Grosso do sul, em relação ao atendimento, produtos e serviço prestados. Através de uma pesquisa realizada com associados da agência. O estudo sobre satisfação em cooperativas de crédito torna-se relevante devido ao fato que toda organização que almeja alcançar níveis positivos de satisfação terá que dispor de um quadro de pessoas capacitadas e comprometidas com os objetivos do negócio. Por isso, é necessário pesquisar de que forma a organização poderá investir nesse tipo de comportamento, visto que o ser humano possui particularidades individuais e a diferença existente entre cada um deles fornece um enorme leque de oportunidades. Convém ressaltar que este estudo se justifica também pela sua contribuição prática, pois, a partir do reconhecimento, por parte das cooperativas, da percepção dos associados sobre a satisfação, o estudo pode auxiliar no desenvolvimento de políticas e práticas de gestão, visando tornar os cooperados mais satisfeitos e envolvidos com os valores da cooperativa. 
Este trabalho encontra-se estruturado em seis seções, introdução. Na seção dois o referencial teórico. Na seção três, a metodologia que permitiu a realização da pesquisa. Na seção quatro, apresentam-se a análise e discussão dos resultados. Na seção cinco, abordam-se as considerações finais, e por fim, constam as referências bibliográficas utilizadas neste trabalho.

\section{Satisfação do cliente}

Um bom atendimento é essencial para que as empresas desenvolvam um diferencial competitivo no mercado. Para isso, é preciso que as necessidades dos clientes sejam reconhecidas, para que as empresas consigam supri-las, obtendo a sua satisfação. Um dos principais fatores que influenciam na decisão de compra dos clientes, é o bom atendimento e por isso é importante que as empresas se adequem as necessidades de seus clientes para conseguir assim, satisfazê-los. Sobre a satisfação dos clientes Minadeo (2008, p.62) afirma que:

A satisfação é o sentimento de prazer resultante da comparação do desempenho percebido do produto com as expectativas do consumidor, que são influenciadas pelas experiências anteriores, recomendações de amigos, informações e promessas da empresa e dos concorrentes, através da comunicação, propaganda e promoção.

Satisfazer os clientes é uma estratégia das empresas com propósito de alcançar seus objetivos, a satisfação do cliente passa a ser vista como propósito maior da organização e como única forma pela qual ela poderá sobreviver em longo prazo. As empresas atualmente vêm "competindo" cada vez mais na busca em conquistar e reter os clientes, ofertando inúmeros benefícios que possam lhe satisfazer e impeçam com que os clientes procurem a concorrência. Kotler e Armstrong (2003, p.156) contribuem demonstrando o custo que a perda de um cliente pode gerar a empresa:

A perda de um cliente representa mais do que a perda da próxima venda; a empresa perde o lucro de todas as compras futuras daquele cliente, para sempre e ainda há o custo de reposição daquele cliente de acordo com pesquisas, o custo incorrido para atrair um novo cliente é cinco vezes maior que o custo para manter um cliente atual fiel e satisfeito. Pior ainda leva alguns anos para o novo cliente comprar na mesma proporção que o antigo.

De acordo com Vavra (1993), os clientes insatisfeitos além de buscarem a concorrência, não medirão esforços para demonstrarem suas queixas e insatisfações para outras pessoas, as quais poderiam ser clientes em potencial. Ao compartilhar sua insatisfação sobre determinada empresa esses clientes, transmitem sua experiência a outras pessoas que também podem multiplicar essa informação de forma sucessiva a outros, criando um circulo vicioso de difamação. Ou seja, um cliente insatisfeito pode ser muito mais prejudicial do que se imagina.

As empresas devem observar e mensurar o nível de satisfação de seus clientes. Por meio disso, é possível observar possíveis mudanças no desempenho de vendas e nos resultados financeiros da empresa. "Clientes satisfeitos tendem a comprar novamente da mesma empresa." (MINADEO, 2008, p.63). Para isso a atenção da empresa é fundamental no relacionamento com o cliente, em vista a alcançar melhores níveis de satisfação.

\subsection{Fidelização do cliente}

A fidelização dos clientes é algo que vem sendo galgado pelas empresas atualmente, por meio dela tem-se certeza de compras futuras, uma vez que o cliente criou um vinculo com a empresa. No sentido da necessidade de desenvolvimento que possa aproximar cliente e empresa, Dias (2003, p.30o), afirma que "fidelizar ou reter o cliente é o resultado de uma estratégia de marketing que tem como objetivos gerar frequência de compra dos clientes, aumentar as vendas por cliente e 
recompensar o cliente por compras repetidas". O bom relacionamento com o cliente deve ser construído com o objetivo de estabelecer relações de parceria, para isso, é importante conhecer os conceitos de lealdade e fidelidade que permeiam a relação entre consumidor e empresa.

Segundo Kotler e Bloom (1998), as teorias de marketing têm evoluído com o passar do tempo, mudando um pouco o seu foco. No passado as empresas preocupavam-se apenas em fechar uma venda, hoje buscam conquistar uma relação entre a empresa e consumidores, por meio da obtenção de informações relevantes, como por exemplo, estilo de vida e dados demográficos. Isto gera a construção de melhores relacionamentos entre empresas e clientes.

De acordo com Las Casas (2010, p.28), fidelidade significa que "os clientes continuam a comprar de uma empresa porque acreditam que ela tenha bons produtos ou serviços." Ainda Las Casas (2010, p. 29): Nenhuma empresa pode satisfazer todas as necessidades de todos os consumidores. Portanto, é preciso concentrar-se no publico alvo da organização e fazer todo o possível para conservá-los, elaborar políticas de preços, linhas de produtos e níveis de serviços voltados para o crescimento e fidelidade.

As empresas devem investir na implantação de estratégias de fidelização para atingir da melhor maneira o seu público alvo. Uma boa fidelização faz com que os clientes pensem antes de trocar de empresa, tornando-se assim um fator de diferenciação no mercado. "Clientes satisfeitos são menos sensíveis a preço, falam bem da empresa e de seus produtos a outras pessoas e permanecem fiéis por um período mais longo." (KOTLER E ARMSTRONG, 2003, p. 477). Percebe-se que de longe, a fidelização dos clientes é um dos fatores fundamentais para o sucesso das empresas, visto que os custos para atração de novos clientes são muitos significativos devido à concorrência existente no mercado. "Portanto, a retenção de clientes é de longe mais importante que a atração de clientes." (VAVRA, 1993, p. 17).

Para que ocorra a fidelização dos clientes, é necessário antes de qualquer coisa, que as empresas tenham a fidelidade de seus funcionários e de seus acionistas, criando-se um valor constate para a empresa. (LAS CASAS, 2010). "Atender às expectativas dos clientes irá apenas satisfazer os clientes; excedê-las irá encantá-los.” (KOTLER, 1999, p. 21). É essencial que as empresas que buscam a fidelização de seus clientes, consigam maravilhar os mesmos, fazendo com que o diferencial daquela empresa seja de fato percebido. Isso se dá, por meio da prestação de um serviço de excelência, que supere as expectativas dos clientes.

De acordo com Kotler (1999), é necessário que as empresas consigam evidenciar seus pontos fortes para seus clientes, buscando a diferenciação perante seus concorrentes. Elas devem adotar estratégias robustas e inovadoras no mercado, pois é preciso fazer muito melhor que os concorrentes para superar as expectativas dos clientes. Na percepção de Lovelock e Wirtz (2006) pode-se constatar também, que um bom relacionamento entre a empresa e seus clientes fiéis, tem o potencial de gerar uma corrente contínua de lucros, podendo esses clientes serem considerados um ativo financeiro da empresa, aumentando seu valor em uma possível venda. Sendo assim, os esforços voltados ao marketing para tais relacionamentos, podem ser vistos não como uma despesa e sim como um investimento futuro.

\subsection{Atendimento ao cliente}

O cliente espera que a organização reconheça sua importância e de sua solicitação. O funcionário, além de reconhecer, deve favorecê-lo, com auxílio a informações adequadas. O consumidor exigente não quer receber apenas um bom atendimento como outro qualquer; ele quer e exige o melhor atendimento possível. Alguns fatores devem ser considerados no atendimento, tais como cordialidade e atenção, respeito, rapidez, facilidade e praticidade nas transações, qualidade do produto, preços entre outros. Assim, uma forma de conquistar os clientes é investindo em praticidade e comodidade no atendimento, evitando burocracia. As empresas precisam trabalhar de 
forma a criar um ambiente organizacional que considera a satisfação de seus consumidores como prioridade, pois e ela que garante a perenidade da empresa.

Os clientes gostam de ser bem atendidos, atualmente saber o nome do cliente é um diferencial que as empresas buscam. Essa ação transmite ao cliente reconhecimento e valorização por parte do estabelecimento, criando laços de amizade e fidelidade que são fortalecidos aliados ao bom atendimento, qualidade do produto e preço, dentre outras vantagens que podem encantar o cliente.

O segredo para empresa é ser a solução para o cliente e não o problema, pois no mundo globalizado de hoje, os clientes estão cada vez mais exigentes e com menos tempo para esperar o atendimento. Os clientes anseiam por segurança, as empresas devem mostrar que é seguro negociar, tende a ser honestas ao oferecer os produtos, evitando criar altas expectativas, mas procurando sempre fazer mais do que prometeu, como esclarece Robert J. Rauscher apud Detzel e Desatnick (1995,p.55):

Uma das maneiras de provar serviços consistentes ao cliente é fazer com que cada funcionário focalize sua atenção na maneira como ele/ela afeta o cliente final e identificar maneiras para exceder consistentemente suas expectativas. Ao mesmo tempo em que se devem exceder as expectativas, é importante ao realizar a venda ou serviço para o cliente, elogiar a escolha feita, porém que este elogio seja feito com sinceridade, para surtir mais efeito diante do cliente, que terá mais confiança no vendedor ou prestador e na empresa na qual fez sua escolha. O cliente é o principal elemento formador de uma empresa, é este o termômetro de análise, para saber se a mesma está tendo ou não sucesso com as suas vendas e serviços. A principal ferramenta que conquista todo e qualquer cliente é o atendimento, sendo que a qualidade deste é indiscutível para o resultado final, ou seja, a compra de um determinado produto ou um serviço realizado. Neste sentido, entende-se que o cliente fiel é aquele que está satisfeito com o atendimento e, que torna-se parceiro comercial da empresa, devido ao grau de satisfação com as atividades executadas.

A qualidade no atendimento é um dos principais fatores para manter a empresa produtiva e competitiva no mercado, esta realidade é apontada como positiva em todos os níveis organizacionais. Segundo Godri (1994, p. 59) "Atendimento é sinônimo de empatia e atenção." Ou seja, o cliente deve ser tratado com prioridade, deve ser ouvido, acompanhado, tratado preferencialmente pelo nome e, acima de tudo, com respeito as suas decisões e opiniões.

Os clientes devem ser a prioridade da empresa, pois desta forma, os funcionários conseguem assimilar a importância do mesmo para a permanência da organização no mercado. Isto significa que o colaborador deve servir o cliente, atendendo da melhor forma possível sempre que o mesmo necessite. Para um bom atendimento deve-se evitar demora, tanto no atendimento pessoal, como virtual, sendo que neste último meio de comunicação é precioso evitar deixá-lo na espera. Isto porque atendimento virtual é um excelente instrumento de comunicação com os clientes atualmente, mas deve ser utilizado de forma adequada, pois um atendimento ruim pode fazer com que o cliente passe para a concorrência.

Ao executar o atendimento, deve-se priorizar o vínculo humano, ou seja, primeiro o cliente, depois o lado comercial, lembrar sempre que cada cliente é único, que não há dois iguais e que de cada um depende a permanência da empresa no mercado. $O$ atendimento ao cliente não se restringe apenas ao momento da compra, mas também o pós-venda, a empresa deve utilizar processos de comunicação para saber a opinião do cliente em relação ao atendimento, produtos e serviços adquiridos, fortalecendo assim, a parceria empresa/cliente. (Detzel, Desatmick, 1995). 
A corrida pela busca na qualidade do atendimento deve ser constante e inovadora, pois além de visar o lucro estas são opções para a empresa se manter no mercado, deve sempre estar observando tudo ao redor, as oportunidades e acontecimentos existentes, de modo a perceber as possíveis necessidades de cada cliente para poder atingir suas necessidades. Segundo Dantas (2004, p. 36): $\mathrm{O}$ atendimento ao público é uma atividade complexa em que interagem diversos elementos. Para melhorá-lo é preciso que se tenha uma visão global e integrada de todos os aspectos considerados relevantes, mesmo que, num determinado momento, se opte por acatar um ponto determinado.

Com a constante busca pelo crescimento, aumenta-se a demanda de serviço, assim há também necessidade de investir em alternativas que facilitam o processamento e agilidade das informações, mostrando também que não somente com a intervenção humana é possível suprir suas necessidades, mas com a intervenção eletrônica também é possível atender a estas demandas. Segundo Shiozawa, (1993, p. 52):

$\mathrm{O}$ atendimento ao cliente significa, portanto, tudo aquilo que, em conformidade com os requisitos, ou seja, o fornecimento dos produtos ou a prestação dos serviços solicitados ajude a criar o produto ou serviço potencial. Esta definição ajuda a compreender que o cliente é um alvo móvel, ou seja, possui expectativas crescentes.

O atendimento de qualidade promove a satisfação do cliente, o fato de ser bem atendido o torna um parceiro comercial da empresa. Para tanto, se faz necessário à oferta de produtos diferenciados, visto a atual concorrência financeiro-cooperativa. Segundo Kotler (2003, p. 143): "As empresas de serviços bem-sucedidas concentram sua atenção tanto nos empregados quanto nos clientes. Elas compreendem a cadeia de lucro em serviços, que vincula os lucros da empresa à satisfação do empregado e do consumidor". As cooperativas atentas a esse cenário não devem medir esforços para garantir este diferencial, já que a economia atual mostra a necessidade deste serviço, sendo uma realidade requerida no mundo moderno.

Albrecht (1992) menciona o que o cliente busca na hora da operação, ou na solicitação de um serviço, apresentando os quatro níveis de hierarquia de importância para o associado:

[...] Básicos, aqueles atributos absolutamente essenciais da experiência, tangíveis ou intangíveis; sem eles é inútil tentar fazer negócio.

- Esperados, os atributos associados da experiência que o cliente acostumou-se a considerar como fazendo parte da prática geral de negócios.

- Desejados, o cliente não espera necessariamente, mas conhece e aprecia se a experiência os incluir.

- Inesperados, atributos "surpresa", que adicionam valor para o cliente além dos seus desejos ou expectativas normais (ALBRECHT, 1992, p. 105).

Serviços de qualidade são aqueles oferecidos com preparo técnico adequado, proporcionando satisfação, assim estes serviços devem ser oferecidos pela organização de forma cuidadosa e minuciosamente planejada. $\mathrm{O}$ atendimento de má qualidade, não é bem visto aos olhos do cliente, mas aquele realizado corretamente, na medida em que compreende as necessidades de cada associado, sempre leva ao crescimento gradativo, muitas vezes sem muito esforço, más com retornos significativos. Quando se está à frente de situações que necessitam de bens ou serviços e suas necessidades não são alcançadas, logo percebesse que a qualidade não foi atendida, e consequentemente suas expectativas não foram supridas, proporcionando insatisfação, e afastando a empresa de resultados positivo propiciados por níveis favoráveis de satisfação. 


\section{Procedimentos metodológicos}

A pesquisa pode ser classificada em diferentes possibilidades de acordo com o propósito de estudo. Conforme Teixeira, Zamberlan e Rasia (2009) a classificação do estudo pode ser: quanto aos objetivos, a natureza, abordagem, e procedimentos técnicos. No que diz respeito aos objetivos, esta pesquisa caracteriza-se como exploratória, pois busca identificar o nível de satisfação dos associados em relação ao atendimento e aos serviços prestados pela cooperativa. A natureza deste estudo é descritiva, devido à facilidade de sua aplicação prática e por permitir o estabelecimento de relações entre as variáveis (GIL, 2002). A abordagem do problema é quantitativa e qualitativa. Quanto aos procedimentos técnicos é classificada como estudo de caso.

A coleta de dados foi realizada em uma cooperativa de crédito no estado de Mato Grosso do Sul através de entrevista com 30 associados, por meio de formulário estruturado, com 11 perguntas fechadas e 1 aberta, a duração média da entrevista foi de 6 minutos. Esta amostra de associados foi selecionada através de abordagem aleatória nos dias de realização da pesquisa. As entrevistas foram realizadas na primeira quinzena do mês de setembro de 2018, nos períodos matutino e vespertino na agência.

As questões foram elaboradas através da escala Likert que é constituído por questões do tipo alternativa fixa, que exige que os entrevistados indiquem um grau de satisfação, aonde os valores vão de 1 a 5, ou seja 1 péssimo, 2 ruim, 3 bom, 4 ótimo e 5 excelente, conforme demonstra a figura 1 abaixo. As perguntas foram elaboradas de maneira estratégica envolvendo assuntos sobre relacionamento dos colaboradores com os associados e satisfação com produtos, serviços e atendimento prestado. Os dados com as respostas dos entrevistados inicialmente foram transformados em gráficos pelo Google forms, posteriormente se deu a análise de dados por meio de analise qualitativa e descritiva com apoio da teoria existente na área.

Figura 1- Escala de Likert

\begin{tabular}{|ccccc|}
\hline Péssimo & Ruim & Bom & Otimo & Excelente \\
\hline 1 & 2 & 3 & 4 & 5 \\
\hline
\end{tabular}

Fonte: Malhotra (2001)

As questões visaram identificar o perfil dos associados, sua satisfação e fidelização com a instituição, além de buscar sugestões de melhorias. Para elaboração do questionário foram selecionadas algumas perguntas baseadas em questionários já existentes, criados por outros pesquisadores, sendo eles: Jessica Dal Toé (Estudo de caso da relação dos associados com uma cooperativa de crédito do sul de Santa Catarina), Cleber Zucchinali Macarini (Qualidade no atendimento ao cliente como diferencial das cooperativas de crédito: um estudo na sicredi sul Santa Catarina), Cassiano Fernando Bordim (Análise do nível de satisfação dos associados: um estudo na cooperativa de crédito Sicredi unidade de Porto Lucena e Porto Vera Cruz).

\section{Resultados e discussões}

A seguir será apresentado os principais resultados da pesquisa, divididos em três momentos, perfil dos associados, analise do nível de satisfação e sugestões.

\subsection{Perfil dos associados}

Dos 30 associados entrevistados $40 \%$ são do sexo masculino e $60 \%$ feminino, o tempo de associação varia, porém a maioria cerca de $60 \%$ é associado a mais de 5 anos, $33 \%$ de 1 á 3 anos e $7 \%$ a menos de 1 ano, demonstrando que os clientes em geral possuem um vinculo relativo com a 
cooperativa. No que diz respeito à fidelização 50\% dos associados dizem não possuir conta em outra instituição financeira, entretanto $50 \%$ relata possuir, seja para o recebimento de salário, beneficio entre outros. $\mathrm{O}$ que evidencia a necessidade de ações voltadas à fidelização, uma vez que metade dos cooperados não se utiliza apenas da cooperativa para realização de transações financeiras.

A idade dos associados é diversificada, 30\% têm entre 34 á 41 anos, $27 \%$ entre 42 á $50,23 \%$ entre 18 á 33 e $20 \%$ mais de 51 anos. No estado civil $63 \%$ são casados, $23 \%$ solteiros e $14 \%$ viúvos ou divorciados. $\mathrm{Na}$ escolaridade dos respondentes, 37\% possuem ensino fundamental, 33\% ensino médio, $20 \%$ ensino superior e $10 \%$ possuem pós-graduação. Percebe-se que há um percentual significativo de pessoas com baixa formação cerca de $70 \%$ possuem apenas ensino fundamental ou médio.

Entre os entrevistados, $46 \%$ possui renda entre R $\$ 954,00$ a $\mathrm{R} \$ 1.908,00$, seguido por $27 \%$ entre $\mathrm{R} \$ 2.862$,oo até $\mathrm{R} \$ 3.816,00,20 \%$ entre $\mathrm{R} \$ 4.770$,00 a $\mathrm{R} \$ 7.632$,oo e apenas $7 \%$ acima de $\mathrm{R} \$ 14.310$,oo. Identificar a renda mensal do cooperado ajuda na definição de estratégias, e oferecimento de produtos diferenciados que abrangem todas as classes sociais. Percebe-se que a maioria do publico entrevistado são pessoas que ganham entre $\mathrm{R} \$ 954,00$ a $\mathrm{R} \$ 3.816,00$.

\subsection{Análise nível de satisfação}

O oferecimento de produtos e serviços que correspondam às expectativas do cliente é sem duvida um grande passo para satisfação, trabalhar com atenção no público alvo do negócio, buscando sempre ofertar os produtos ou serviços certos na hora certa ao público certo, se torna uma diferenciação no mercado. Entender o desempenho dos produtos e serviços da empresa é uma oportunidade na busca de melhorias e criação de estratégias mais assertivas. A figura 2 abaixo mostra a avaliação dos associados em relação aos produtos e serviços oferecidos, 50\% dos entrevistados consideram os produtos e serviços excelentes, $40 \%$ consideram ótimo, apenas $10 \%$ consideram como bom, em nem uma resposta foi considerado como ruim ou péssimo, demonstrando que grande a maioria dos associados esta satisfeita ou não estão insatisfeitos.

Figura 2 - Produtos e serviços (\%)

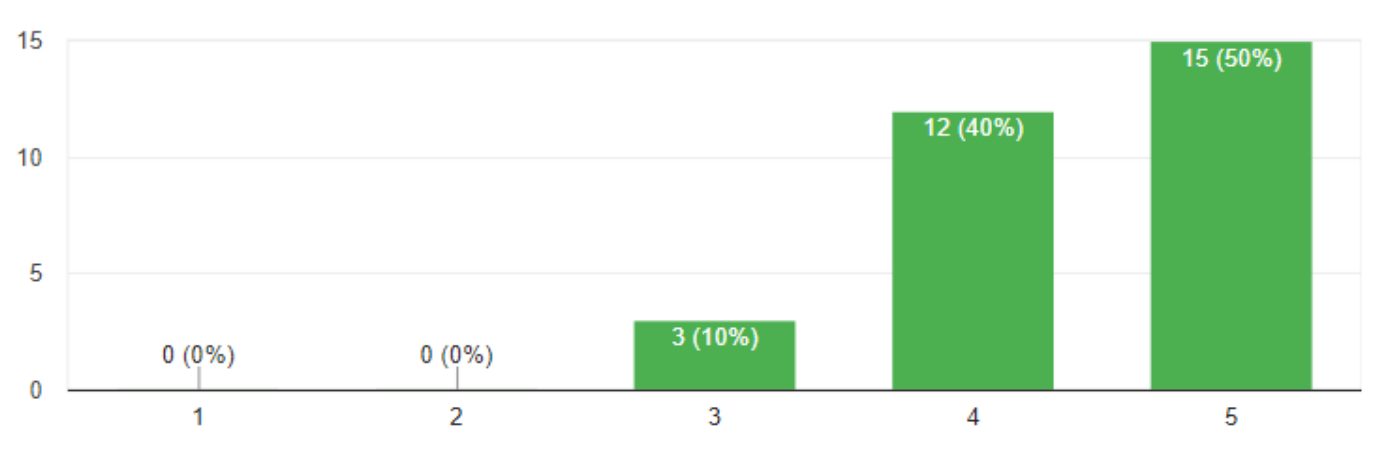

Fonte: Dados da pesquisa (2018)

Para Oliveira (1996), a qualidade deve estar sempre sendo buscada, e fazem parte das metas organizacionais, podendo ser encontradas nos produtos, nos serviços, na eficácia e eficiência dos colaboradores e principalmente, no que tange a satisfação do cliente, sendo estas as atribuições que o cliente faz ao produto ou serviço. Compreende-se que a cooperativa vem realizando um excelente trabalho em relação à satisfação com os produtos e serviços oferecidos já que $90 \%$ dos associados relatam ser ótimo e excelente, comprovando assim a qualidade nos produtos e serviços da cooperativa. Como mencionado por Oliveira, à qualidade é indispensável e percebida pelo cliente 
nos produtos e serviços da empresa, ao contrapor este fato com a realidade da cooperativa, constatase que a mesma vem aliando o conhecimento teórico ao pratico fato comprovado em seus resultados.

A figura 3 abaixo expressa o nível de satisfação em relação ao atendimento prestado pelos colaboradores, $60 \%$ avaliaram como excelente, $26,7 \%$ ótimo e $13,3 \%$ acreditam ser bom, não apresentando nem uma avaliação ruim ou péssima, mostrando que o atual atendimento prestado está apresentando excelentes resultados e contribuindo diretamente para a satisfação dos associados, porém com possibilidades de melhoria e aumento do nível de satisfação.

Figura 3 - Atendimento colaboradores em geral(\%)

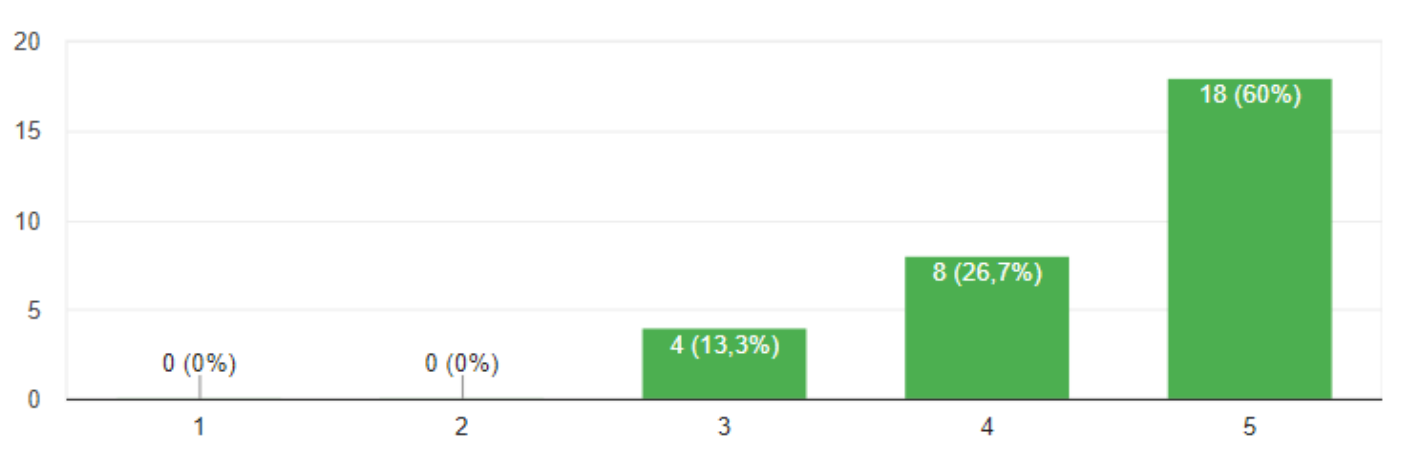

Fonte: O autor do trabalho (2018)

Segundo Kotler (2003) O atendimento de qualidade fidelizará o associado, independente se o problema que ele está querendo resolver irá demorar ou não para ser solucionado, muitas vezes somente o fato de ser bem atendido o torna um parceiro comercial da instituição, devido a este grau de satisfação. Fato percebido na fala dos entrevistados ao dizerem que sempre são bem atendidos, o que demonstra que o atendimento de qualidade é indispensável para garantir a satisfação e fidelização do associado.

Em relação ao tempo de espera no atendimento pode se observar na figura 4, que $16,7 \%$ dos respondentes consideram como excelente, 46,7 ótimo, e 36,7\% bom, não apresentando nem um percentual de respostas ruim ou péssimo, evidenciando que o tempo esta influenciando na satisfação dos associados devido a grande maioria os considerar como ótimo e excelente. Ao responderem os associados comentaram que a mudança feita no atendimento dando preferência ao associado tem contribuído muito para a rapidez no atendimento, e demonstra os benefícios de serem cooperados.

Figura 4 - Tempo de espera no atendimento (\%)

15

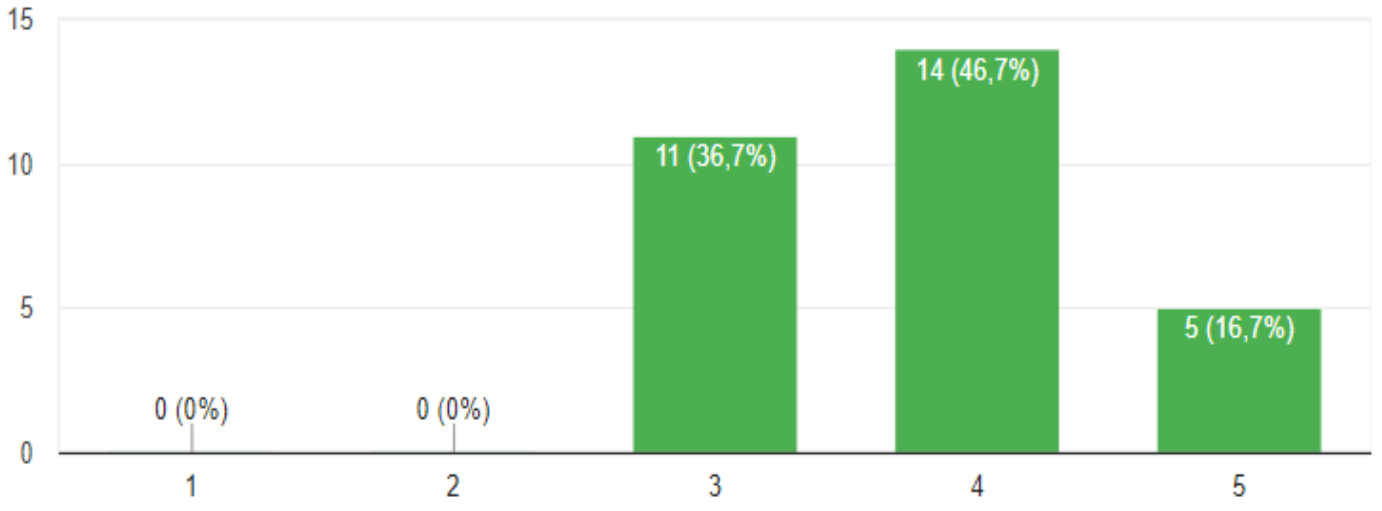

Fonte: O autor do trabalho (2018) 
Entretanto existe um valor significativo 36,7 que avaliam como bom, isso ilustra certa imparcialidade e tendência à insatisfação. Serviços de qualidade esta diretamente ligada ao tempo de espera no atendimento, assim estes serviços devem ser oferecidos pela instituição de forma cuidadosa e minuciosamente planejada. Atualmente o tempo de espera é um dos grandes fatores de insatisfação observado nas instituições financeiras, fato que leva muitos clientes a migrarem para instituições $100 \%$ online, onde os mesmos não precisam aguardar para serem atendidos.

Conforme a figura 5, ao questionar sobre o atendimento das expectativas dos associados em relação aos produtos e serviços $43,3 \%$ avalia serem excelentes, $36,7 \%$ ótimo e $20 \%$ avaliou como bom, não apresentando nem um percentual de resposta ruim ou péssimo. Nota-se que em relação às expectativas as mesmas vêm sendo atingidas de maneira satisfatória, pelo grande percentual cerca de 8o\% somando excelente e ótimo que atinge as expectativas, o que demonstra que a cooperativa está satisfazendo em grande maioria seus associados.

Figura 5 - Produtos e serviços atendem as expectativas (\%)

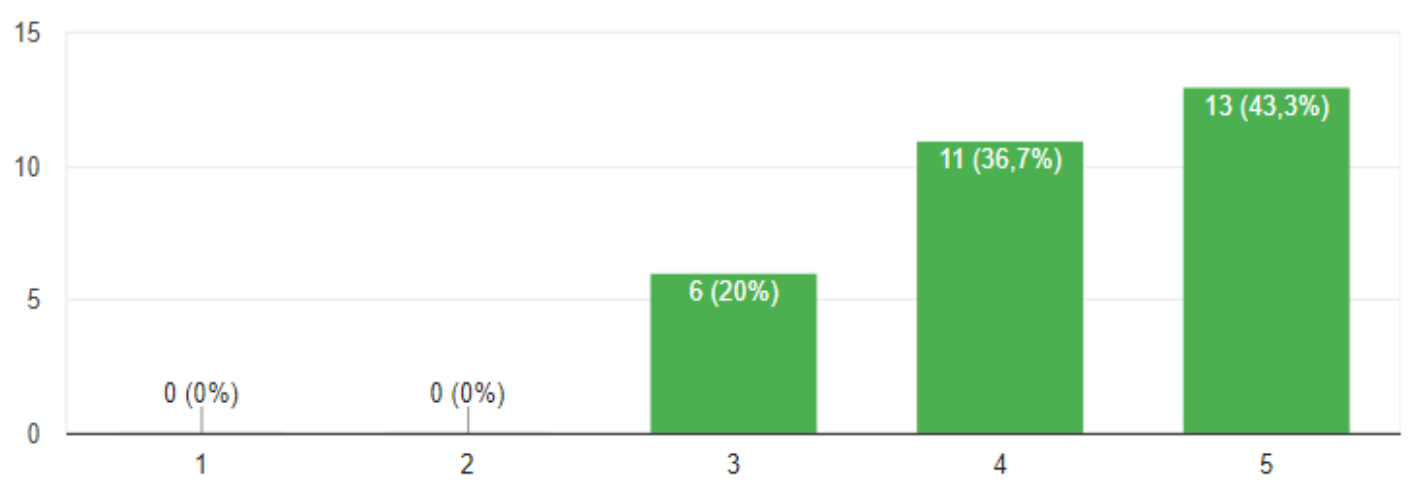

Fonte: $\mathrm{O}$ autor do trabalho (2018)

Segundo Kotler (2000), produto e serviços representam algo que pode ser oferecido a um mercado para a sua apreciação, uso ou consumo na tentativa de satisfazer um desejo, necessidade ou demanda. Existem alguns aspectos da estratégia que podem influenciar o comportamento de compra do consumidor. Porém percebe-se que grande parte dos associados tem suas expectativas supridas pela cooperativa através dos produtos e serviços proporcionando-lhes satisfação em se tratando dessa variável.

Quanto à qualidade dos serviços oferecidos pela cooperativa, 43,3\% julgam ser excelente, $43,3 \%$ ótimo e $13,3 \%$ bom e nem um percentual de resposta para ruim ou péssimo. Conforme demonstra a figura 6 . Referente à utilização dos serviços os mesmo relatam que percebem uma ótima qualidade e nunca tiveram problemas em relação a esse fator. Pela cooperativa oferecer os mesmos produtos que os bancos tradicionais seus serviços apresentam uma excelente qualidade, podendo ser percebida pelas respostas que $86,6 \%$ somando-as avaliam como ótimo e excelente. 
Figura 6 - Qualidade dos serviços (\%)

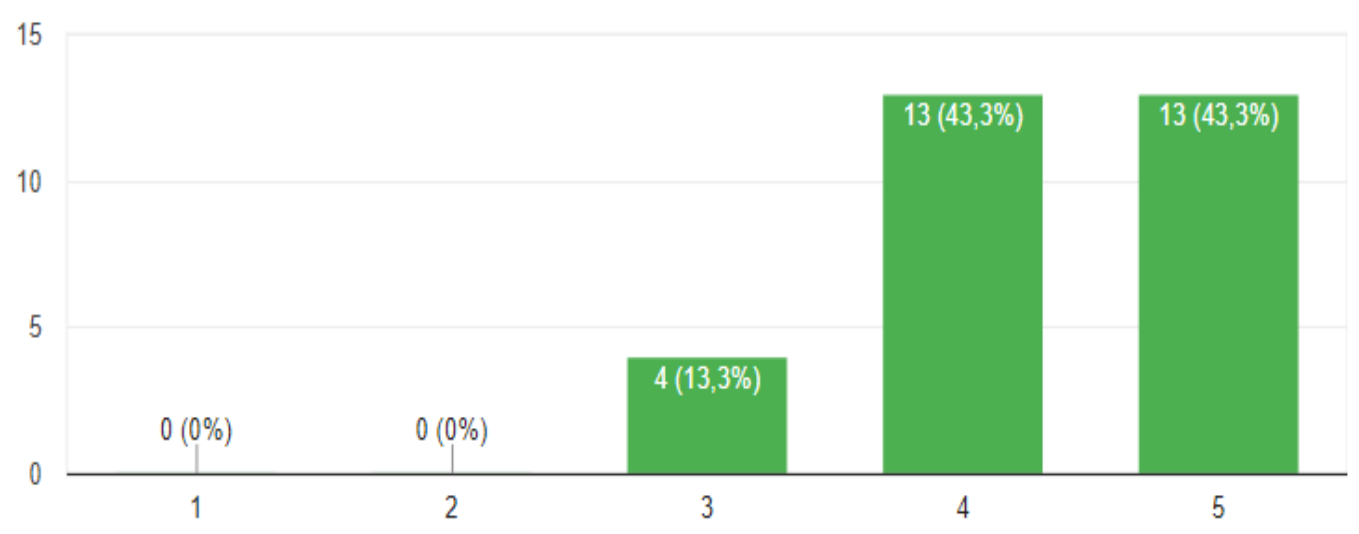

Fonte: O autor do trabalho (2018)

Para Oliveira (1996), a qualidade deve estar sempre sendo oferecida, para a melhoria da satisfação, sendo este elemento indispensável pelo cliente ao adquirir um produto ou serviço. Entende-se que qualidade dos serviços é um dos fatores que mais pode levar a insatisfação, em se tratando de qualidade a cooperativa apresenta uma excelente avaliação por parte dos associados entrevistados.

Ao questionar os associados sobre a satisfação que sentem em relação a fazer parte da cooperativa, $63,3 \%$ reponderam ser excelente, $26,7 \%$ ótimo, $6,7 \%$ bom e apenas $3,3 \%$ diz ser péssimo, não apresentando nem um percentual de resposta como ruim, conforme figura 7 . O que demonstra que a maioria dos entrevistados está satisfeita em serem associados do Sicredi com uma parcela de excelente e ótimo somadas dando um total de 90\% de satisfação em ser associados, evidenciando o trabalho que vem sendo feito para satisfazer diariamente os associados nas suas necessidades junto a cooperativa.

Figura 7 - Satisfação de ser associado (\%)

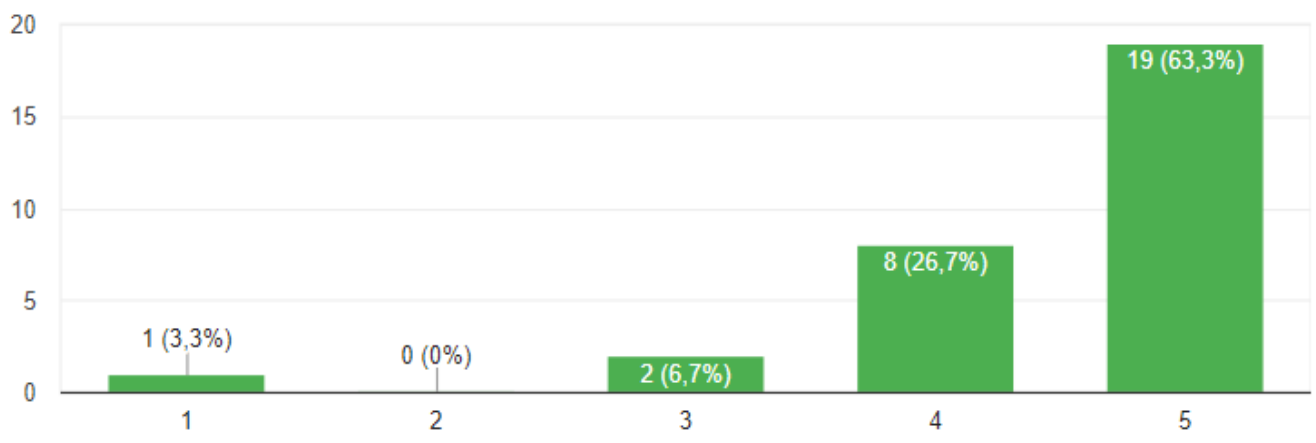

Fonte: $\mathrm{O}$ autor do trabalho (2018)

Minadeo (2008) descreve que as empresas devem observar e mensurar o nível de satisfação de seus clientes. Por meio disso, é possível observar-se possíveis mudanças no desempenho de vendas e nos resultados financeiros da empresa. Um associado satisfeito garante a cooperativa um maior resultado uma vez que satisfeitos os mesmos tendem a usar mais os produtos e serviços da cooperativa. Percebe-se que cerca de 90\% somando excelente e ótimo consideram estar satisfeito em ser associados da cooperativa. 
Conclui-se na figura 8 , que a grande maioria, cerca $97 \%$ dos associados indicariam o Sicredi para um amigo se associar, contra apenas 3\% que não indicariam. O que demonstra o alto índice de satisfação por parte dos associados, pois em geral só se indica algo a um amigo se realmente esse produto ou serviço for bom e apresentar uma boa qualidade.

Figura 8 - Indicação (\%)

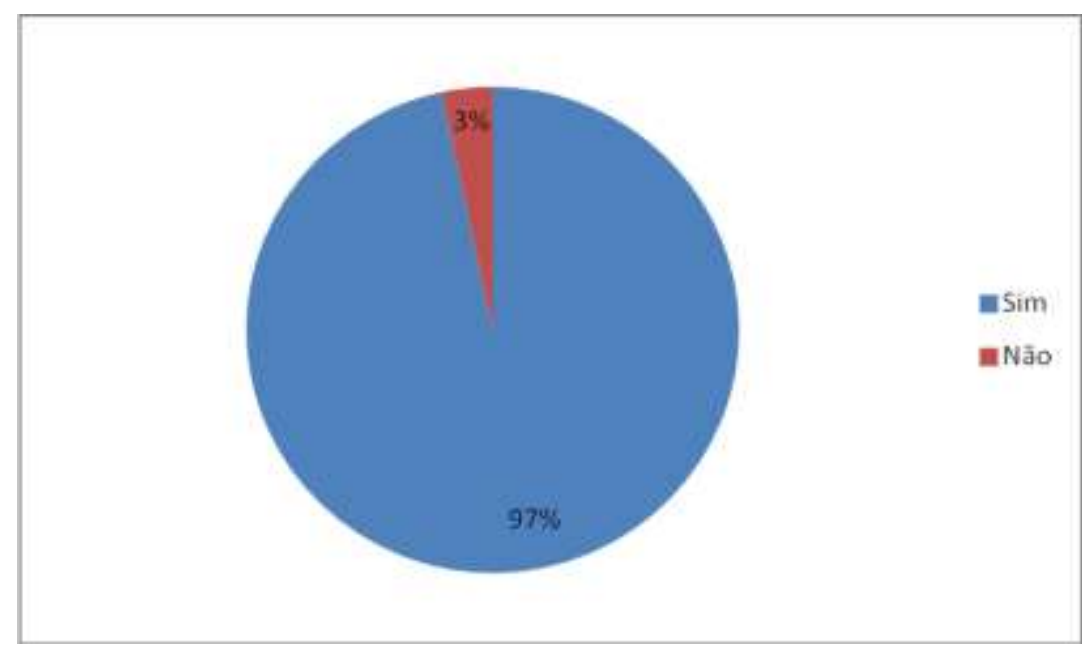

Fonte: $\mathrm{O}$ autor do trabalho (2018)

De acordo com Vavra (1993), os clientes insatisfeitos além de buscarem a concorrência, não medirão esforços para demonstrarem suas queixas e insatisfações para outras pessoas, as quais poderiam ser clientes em potencial. Com isso a cada pessoa que ele compartilhe suas experiências ruins, essas podem se multiplicar sucessivamente. Ou seja, um cliente insatisfeito pode ser muito mais prejudicial do que se imagina. Como a grande maioria dos associados cerca de $97 \%$ indicariam a cooperativa há uma amigo, comprova-se que a satisfação pelos produtos, serviços e atendimento na cooperativa é o fator de influencia na hora da indicação. Além de ser extremamente prejudicial a insatisfação por parte do associado pode criar uma má imagem da empresa frente a futuros cooperados. A propaganda positiva feita pelos próprios associados é sem dúvidas importantíssimas para agregar valor à cooperativa além de não custar nada, uma vez negativa pode causar danos irreparáveis.

\subsection{Sugestões}

A tabela 1 abaixo, mostra as sugestões apontada pelos associados, nem todos os entrevistados deram sugestões, alguns relataram não ter sugestões por estarem satisfeitos com os produtos, serviços e atendimento oferecido pela cooperativa, algumas sugestões como: Melhoria nos terminais de autoatendimento; Apoio as micro e pequenas empresas, através de linhas de crédito especificas, com menos burocracia; Educação financeira e disponibilizar colaboradores no autoatendimento. Foram sugestões que apresentaram maior frequência na resposta por parte dos entrevistados, evidenciando que os mesmos têm sugestões em comum e que seria um ponto de atenção a ser levado em conta pela cooperativa para melhorar a satisfação.

Quando questionados sobre as sugestões para que haja um melhor índice de satisfação foi realizada a seguinte pergunta aos associados: Que sugestão poderia ser dada a cooperativa, para que melhore a qualidade na prestação de serviço/produtos e atendimento? As principais respostas estão expostas na tabela 1, a seguir. 
Tabela 1 - Sugestões

\begin{tabular}{|l|}
\hline \multicolumn{1}{|c|}{ Sugestões } \\
\hline Redução de taxas de juros, funcionários competentes e preparados para o atendimento; \\
\hline $\begin{array}{l}\text { Recebimento da guia do FGTS (no momento a cooperativa não tem convênio com esse } \\
\text { pagamento); }\end{array}$ \\
\hline Facilidade na atualização cadastral; \\
\hline Passar mais informações sobre a cooperativa; \\
\hline Melhorias nos terminais de autoatendimento, são ultrapassados; \\
\hline Sempre disponibilizar colaboradores no autoatendimento; \\
\hline Aumentar a taxa de juros para aplicação em poupança; \\
\hline Agilidade no processo de liberação de crédito; \\
\hline $\begin{array}{l}\text { Apoio à micro e pequenas empresas, através de linhas de crédito especificas, com menos } \\
\text { burocracia e educação financeira. }\end{array}$ \\
\hline
\end{tabular}

Fonte: O autor do trabalho (2018)

Percebe-se que as sugestões são na maioria feedbacks construtivos, que se levado em conta pode melhorar significativamente a satisfação dos associados uma vez que segundo Oliveira (1996), a qualidade deve estar sempre sendo buscada e fazem parte das metas organizacionais, podendo ser encontradas nos produtos, nos serviços, na eficácia e eficiência dos colaboradores e principalmente, no que tange a satisfação do cliente, sendo estas as atribuições que o cliente faz ao produto ou ao serviço. As sugestões são uma ótima fonte de ideias para a melhoria da cooperativa, e para o alcance de melhores índices de satisfação em relação aos produtos, serviços e atendimento.

\section{Considerações Finais}

Atualmente o mercado financeiro vem apresentando um nível de concorrência cada vez maior no setor bancário/cooperativista. Assim, avaliar o nível de satisfação de seus associados em relação aos produtos serviços e atendimento, é uma excelente oportunidade de identificar aspectos relacionados à forma como estes enxergam e avaliam a instituição. Neste contexto este trabalho apresentou a seguinte questão problema: $\mathrm{O}$ atendimento e os serviços prestados pela cooperativa de crédito a seus associados tem gerado nível de satisfação favorável. Para responder esse questionamento teve-se como objetivo traçado identificar e analisar o nível de satisfação dos associados da cooperativa de crédito em Mato Grosso do sul, em relação ao atendimento e ao serviço prestado por esta unidade.

Foi percebido que o atendimento é considerado pelos associados como um diferencial da cooperativa apresentando cerca de $90 \%$ de avaliação como excelente e ótimo, o que demonstra o empenho dos colaboradores em sempre atender da melhor forma possível, estando dispostos a ajudar, prestar informações corretas, precisas e principalmente transmitir confiança ao associado. $\mathrm{O}$ resultado, ainda confirma o bom relacionamento mantido entre colaboradores e associados, algo que é preciso ser conservado, pois é percebido nos resultados que o mau atendimento é um fator crucial para deixar de ser associado.

Em relação aos produtos e serviços se comprovou ser adequada a demanda, já que a pesquisa evidenciou que $90 \%$ dos associados relatam ser ótimo e excelente, comprovando assim que a qualidade nos produtos e serviços é essencial mesmo este sendo intangíveis nas instituições financeiras. Como avaliação geral da pesquisa, obteve-se um bom índice de satisfação dos associados com a instituição, tanto no que diz respeito aos serviços prestados, produtos, condições físicas da unidade e principalmente com a qualidade do atendimento prestado.

Entre outros fatores, cabe destacar a importância de se preservar os pontos fortes, conforme a pesquisa identificou: o bom atendimento, confiança, cortesia, boa comunicação e os preços e taxas 
de juros competitivos. Ademais a pretensão deste trabalho não foi esgotar os aspectos que contribui para satisfação, más apenas elencar os que são mais significativos e estão diretamente relacionados à satisfação. As informações deste estudo podem auxiliar no desenvolvimento da cooperativa de crédito, pois os dados demonstram a opinião dos associados e trouxe sugestão de ações de estratégias praticas que podem ser aplicadas a organização. Desta forma, fica a sugestão de efetuar pesquisas desse caráter em outras cooperativas de crédito em demais estados, para averiguar se todas seguem o mesmo padrão na satisfação dos associados ou para serem feitas comparações interestaduais.

\section{Referências}

ALBRECHT, K. Revolução nos serviços. São Paulo: Pioneira, 1992.

BURIGO, Fábio Luiz. Sistema Nacional de Crédito Rural: uma tragetória de privilégios, crises e oportunidades. In: Ensaios sobre o Cooperativismo Solidário. Londrina: Midiograf, 2010.

DANTAS, Edmundo Brandão. Atendimento ao público nas organizações: quando o marketing de serviços mostra a cara. Brasília/DF: SENAC, 2004.

DETZEL, Denis H; DESATMICK, Robert L. Gerenciar bem é manter o cliente. São Paulo: Pionera, 1995.

DIAS, Sérgio Roberto (Coord). Gestão de marketing. São Paulo: Saraiva, 2003.

GIL, Antônio Carlos. Como elaborar projetos de pesquisa. 2. ed. São Paulo: Atlas, 2002.

GODRI, Daniel. Conquistar e manter clientes. 32. ed. Blumenau-SC: Eko, 1994.

KOTLER, Philip; BLOOM, Paul N. Marketing para serviços profissionais. São Paulo: Atlas, 1998.

KOTLER, P. Conquistando clientes, mantendo-os e aumentando sua fidelidade. In:Marketing para o século XXI: como criar, conquistar e dominar mercados. São Paulo: Futura, 1999.

KOTLER, Philip. Administração de Marketing: Edição Novo Milênio. São Paulo: Pretice Hall. 2000.

KOTLER, Philip; ARMSTRONG, Gary. Princípios de marketing. 9 ed. São Paulo: Prentice Hall, 2003.

KOTLER, Philip. Marketing essencial: conceitos, estratégias e casos. Tradução de Sabrina Cairo. São Paulo: Prentice Hall, 2005.

LAS CASAS, Alexandre Luzzi. Administração de Marketing: conceitos, planejamento e aplicações a realidade brasileira - $1^{\underline{a}}$ Ed $-3^{\underline{a}}$ reimpr.- São Paulo: Atlas.2010.

LOVELOCK,Christopher, WIRTZ, Jochen. Marketing de Serviços: pessoas, tecnologia e resultados. São Paulo: Pearson Prentice Hall, 2006.

MINADEO, Roberto. Gestão de Marketing: fundamentos e aplicações. São Paulo: Atlas, 2008.

OLIVEIRA, S. T. Ferramentas para o aprimoramento da qualidade. São Paulo: Pioneira, 1996. 
PINHO, Diva Benevindes. O Cooperativismo no Brasil: da vertente pioneira à vertente solidária. São Paulo: Saraiva, 2014. Sebrae. Disponível em: www.sebrae.com.br/sites/PortalSebrae. Acesso em: 10 de nov. 2017.

SHIOZAWA, Ruy S.C. Qualidade no atendimento e tecnologia da Informação. São Paulo: Atlas S.A, 1993.

TEIXEIRA, Enise Barth; ZAMBERLAN, Luciano; RASIA, Pedro Carlos - Pesquisa em administração: Ijuí, Rio Grande do Sul, Brasil, 2009.

VAVRA, T. G. Marketing de Relacionamento. After marketing. São Paulo: Atlas, 1993.

VAVRA, Terry G. Marketing de relacionamento: after marketing. São Paulo: Saraiva, 2001. 